\title{
Tribology of multilayer coatings for wear reduction: A review
}

\author{
Mahdi KHADEM ${ }^{1,2}$, Oleksiy V. PENKOV ${ }^{2}$, Hee-Kyung YANG ${ }^{1}$, Dae-Eun KIM ${ }^{1,2, *}$ \\ ${ }^{1}$ Department of Mechanical Engineering, Yonsei University, Seoul 03722, Republic of Korea \\ ${ }^{2}$ Center for Nano-Wear, Yonsei University, Seoul 03722, Republic of Korea \\ Received: 11 April 2017 / Revised: 09 June 2017 / Accepted: 01 July 2017 \\ (C) The author(s) 2017. This article is published with open access at Springerlink.com
}

\begin{abstract}
Friction and wear phenomena encountered in mechanical systems with moving components are directly related to efficiency, reliability and life of the system. Hence, minimizing and controlling these phenomena to achieve the desired system performance is crucial. Among the numerous strategies developed for reducing friction and wear, coatings have been successfully utilized in various engineering applications to mitigate tribological problems. One of the benefits of coatings is that they may be fabricated using a variety of materials in several different forms and structures to satisfy the requirements of the operating conditions. Among many types, coatings that are comprised of a combination of materials in the form of a multilayer have been gaining much interest due to the added degree of freedom in tailoring the coating property. In this paper, the properties and development status of multilayer coating systems for tribological applications were reviewed with the aim to gain a better understanding regarding their advantages and limitations. Specifically, focus was given to Ti-based and $\mathrm{Cr}$-based coatings since $\mathrm{Ti}$ and $\mathrm{Cr}$ were identified as important elements in multilayer coating applications. Emphasis was given to materials, design concepts, mechanical properties, deposition method, and friction and wear characteristics of these types of coatings.
\end{abstract}

Keywords: multilayer coating; friction; wear; tribology

\section{Introduction}

Friction and wear occur in all mechanical systems with moving components that are in contact with one another. These phenomena are largely responsible for the degradation of system reliability and performance due to excessive energy consumption and progressive loss of material. In this regard, considerable efforts have been devoted to develop effective methods to minimize and control friction and wear [1-3]. One of the methods is to use materials that possess low friction and wear properties in the form of a coating on sliding components. This strategy is highly preferred because fabrication of sliding components using these materials in the bulk form is not a cost effective or practical option for industrial applications. In addition, coatings can provide unique properties and multi- functionality, and therefore, offer superior tribological properties by incorporating different materials that would otherwise not be possible when using such materials in their bulk form [4].

Coatings may be fabricated in a variety of forms and structures using different kinds of materials. Regarding the number of layers, coatings may be single layer, bilayer or multilayer (more than two layers) [5]. As for the microstructure of the coatings, it may range from a simple single homogeneous structure to more complex systems, such as alloyed, composite and gradient structures. Among the coating design concepts, multilayer coatings are particularly attractive because they provide the means to tailor the surface properties with more freedom. For instance, the ability to control residual stress, hardness to elasticity modulus ratio and adhesion to the substrate through

* Corresponding author: Dae-Eun KIM, E-mail: kimde@yonsei.ac.kr 
strategic stacking of coating layers is beneficial for tribological performance improvement [6]. In this regard, the interest in multilayer coatings as an effective solution for the reduction of friction and wear has been growing rapidly.

In this paper, advancements made in the fabrication and development of multilayer coating systems for friction and wear reduction were reviewed. The aim was to provide a comprehensive overview of multilayer coatings for tribological applications and gain a better understanding of their advantages and limitations. The type of materials used for such coatings along with their design concepts, deposition method, mechanical properties, and friction and wear characteristics were investigated. Specifically, Ti-based and Cr-based coatings were emphasized since $\mathrm{Ti}$ and $\mathrm{Cr}$ were identified as elements used widely in many multilayer coating applications. Nevertheless, other types of multilayer coatings were also reviewed for comparison.

\section{Materials and design}

In recent years, many new materials with superior mechanical properties have been synthesized and utilized for tribological applications. These materials have been effectively incorporated in fabrication of functional coatings to reduce friction and wear.
Particularly, materials used for multilayer coatings may be categorized as ceramics, metals, solid lubricants, and diamond-like carbon (DLC) [7]. Ceramics (oxides, carbides, and nitrides of transition metals) are introduced to multilayer structures to provide sufficient hardness and wear resistance due to their strong interatomic bonding. Moreover, they have excellent adhesion to metal substrates and hard alloys. A classification of hard ceramic coatings for wear protection according to their bonding characteristics is presented in Fig. 1. The downside of hard ceramic coatings is their brittleness and relatively high coefficient of friction (COF) (0.3 to 0.8) [8]. Therefore, they have limitations in tribological applications that require inherently low COF. To overcome this issue, materials with inherently low COF (below 0.1), also known as solid lubricants (e.g., $\mathrm{MoS}_{2}, \mathrm{WS}_{2}, \mathrm{PbO}$, and graphite), are preferable to be employed as the topmost layer $[9,10]$. Such coatings, however, have relatively low hardness and wear resistance. On the other hand, DLC is a unique material that offers outstanding properties, such as extreme hardness, high ductility, chemical inertness, high wear resistance and low COF (0.1 to 0.2). These properties together with optical transparency and biocompatibility make DLC an excellent candidate for a broad range of tribological applications in various industries [11-14]. The structure, composition and

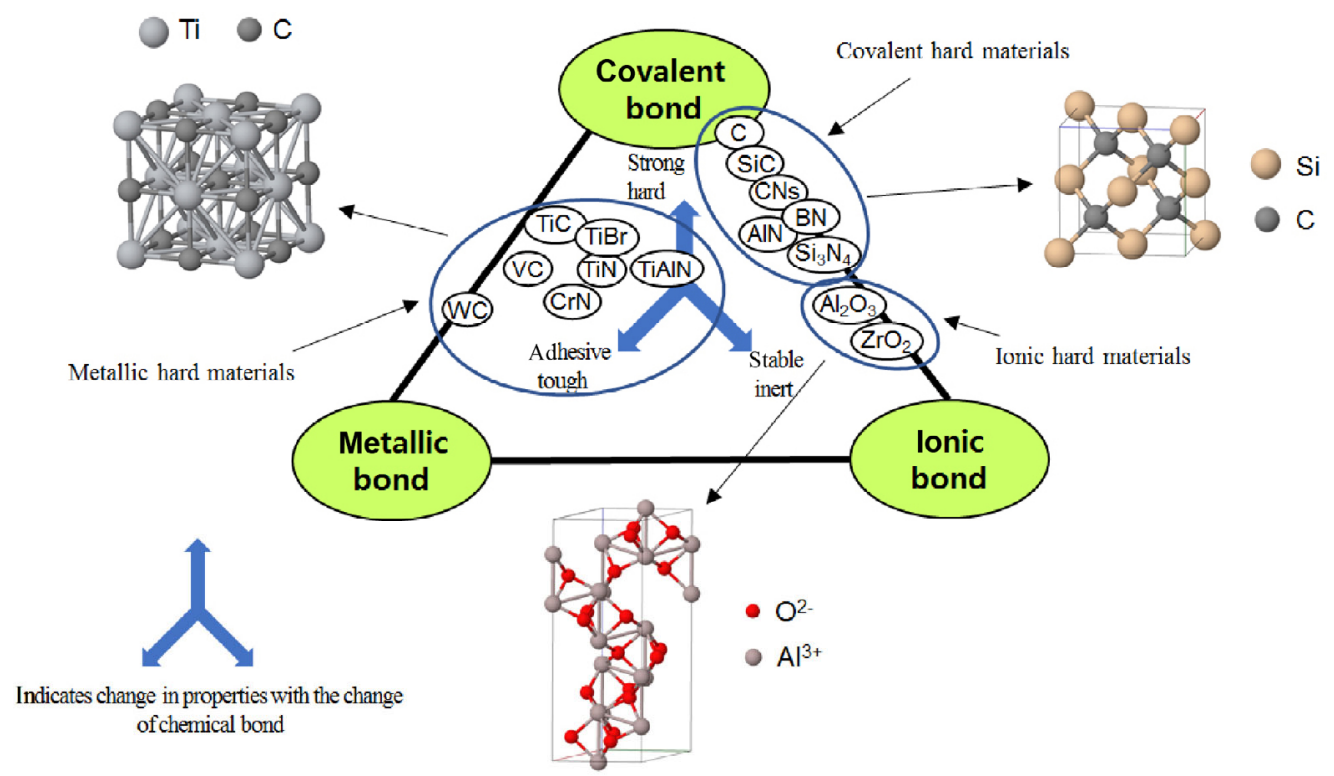

Fig. 1 Classification of different groups of hard ceramic materials on their bonding type and crystalline structure. Adopted from Ref. [6], with permission from Elsevier. 
functionality of DLC coatings vary depending on the deposition method and condition. When DLC structure is $\mathrm{sp}^{3}$-dominant, typically a higher hardness and lower can be expected. However, higher percentage of $\mathrm{sp}^{3}$ also increases the internal stress levels that has negative effects on the coating wear resistance and limits the coating thickness. The main factors that limit the application of DLC in some cases are a high level of internal stress that limits its maximum thickness and relatively poor adhesion to metal substrates.

The coating materials discussed above certainly have merits for specific tribological applications. Nevertheless, their performance may be further enhanced by combining more than one material to produce a composite or a multilayer structure. In the material selection and design process of multilayer coatings, the basic idea is that the strength of one material should cover the weak property of the other so that superior tribological properties can be attained through the synergistic effects of these materials. For instance, a preferred multilayer coating design may be a combination of ceramics with good adhesion, solid lubricants with low COF and DLC with high hardness.

Multilayer coating design with respect to its function and structure considering the material selection of individual layers, interfacial layers and the layer structure regarding sequence and thickness allows for flexible tailoring of surface properties (e.g., hardness to elasticity modulus ratio) and performance (Fig. 2) [6]. Fundamental studies have shown that a proper ratio of hardness to elastic modulus is a major criterion that influences the abrasive wear characteristics of a coating $[3,6]$. Besides hardness, high toughness should also be assured to prevent early coating failure due to crack propagation and fractures. Coatings with high hardness and toughness may be realized through combinations of metallic/metallic, metallic/covalent or metallic/ionic hard materials. Attaining high stability at the interfaces within the coating by the formation of nanocrystalline or multilayer films may help to overcome these problems since interfaces in multilayer coatings serve as sites of energy dissipation and crack deflection leading to higher overall toughness of the coating [6].

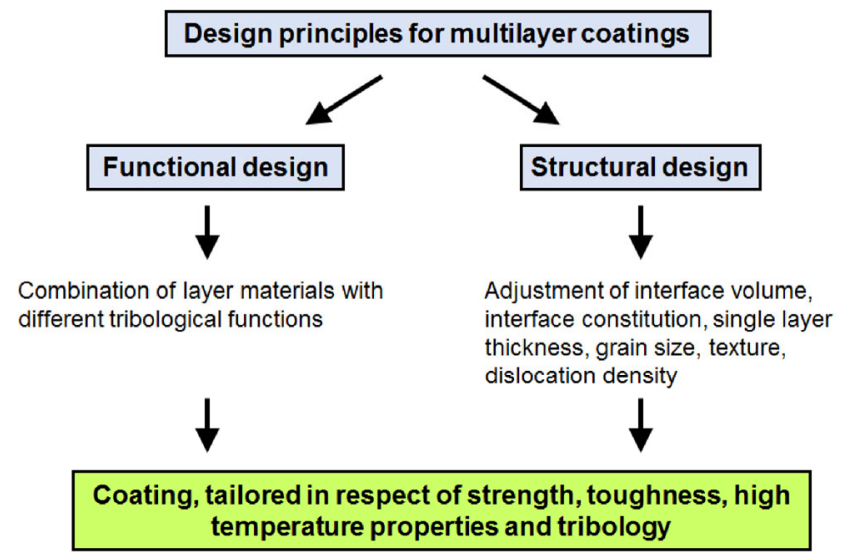

Fig. 2 Design principles of multilayer coatings. Adopted from Ref. [6], with permission from Elsevier.

When it comes to proper material selection, a variety of parameters such as hardness, elastic modulus, thermal expansion coefficient, crystal structure, stress discontinuity between layers and chemical compatibility between the coating and substrate should be considered. To optimize these parameters, one or more interlayers (also known as sublayers or adhesion layers) should be deposited on the substrate prior to deposition of the actual coating. Deposition of an interlayer significantly improves the compatibility between the substrate and coating, which in turn results in better tribological performance [15].

Studies have shown that poor compatibility, mainly regarding chemical bonding, often leads to poor adhesion between the coating and the substrate, which results in coating delamination as the coating thickness increases [16, 17]. In this regard, interlayers for adhesion improvement against the substrate are an essential component of multilayer coatings. Figure 3(a) presents a schematic of supporting layers, together with their role and functionality, in a typical multilayer coating system. The advantages derived by incorporation of the interlayer in designing multilayer coatings were demonstrated by Deng and Braun [16]. In their work, a DLC-based multilayer coating in a graded sequence was developed to optimize adhesion and ductility, which are crucial to attain good tribological performance of DLC coatings. A Ti layer was first deposited onto an AISI 420 steel substrate. Afterward, TiN, TiCN, and $\mathrm{TiC}$ were deposited in sequence to provide sufficient adhesion of DLC to the substrate and to 
ensure smooth boundary transitions. TiN and TiC ("binary" hard materials) are hard coatings with well-known variations in stoichiometry and properties depending on the deposition parameters [18]. A quite similar strategy regarding materials and the deposition sequence was proposed by many other researchers (e.g., Fig. 3(b)) [7, 19-24]. Voevodin et al. [24] demonstrated that the drawbacks of DLC were more pronounced when applied to relatively soft substrates such as steel. They described the role of $\mathrm{Ti}$ and $\mathrm{TiC}$ layers prior to the deposition of DLC as follows: (i) formation of a load support and adhesion promoting underlayer with mechanical characteristics that vary gradually from the substrate to the DLC layer; (ii) separation of hard DLC layers with interlayers of softer material to reduce stresses and cracks; and (iii) use of crystalline interlayers that permit operation of dislocation sources for stress relaxation and deflection of cross-sectional cracks. Furthermore, by deposition of periodically stacked $\mathrm{Ti}$ and $\mathrm{TiN}$ layers, Bemporad et al. [25] overcame the problem of high internal stresses in TiN coatings responsible for limiting their maximum thickness. Considering that thickness plays a major role in tribological systems, obtaining large thickness coatings without compromising adhesion and toughness is highly desirable.

Advantages in tribological properties were also found in alloying binary components with metal/metalloid components (e.g., Ti(C,N)). Su and Kao [20] performed a wear optimization study with respect to the thickness and deposition sequence of Ti-, TiN-, and TiCN-based multilayer coatings. It was found that the coating with a total thickness of $7 \mu \mathrm{m}$ and layer sequence of
TiN/TiCN/TiN had the optimum wear resistance. However, it was found that the wear behavior was strongly dependent on the amount of alloying element [18]. Such investigations were extended to a wide variety of elements such as $\mathrm{Cr}, \mathrm{Zr}, \mathrm{Al}, \mathrm{Si}$, etc. [26-29]. Particularly, Cr-based coatings exhibited the potential to be a good candidate for tribological applications, and in some cases demonstrated better wear resistance than Ti-based coatings [18, 19].

\section{Deposition methods}

In this section, an overview of the deposition methods used for the fabrication of multilayer coatings along with their advantages and disadvantages is discussed. In the past decade, various techniques have been employed for depositing multilayer coatings. The deposition techniques that have been widely used for the fabrication of multilayer coatings may be divided into two broad categories: chemical vapor deposition (CVD) and physical vapor deposition (PVD). To determine the most suitable deposition technique for the fabrication of a multilayer coating for a given material, the effects of the deposition technique on the mechanical and tribological properties of each individual layer should be considered. Though both PVD and CVD techniques have been employed for multilayer coating deposition, the preference seems to be toward PVD techniques. In order to obtain multilayer coatings with good adhesion, mechanical and tribological properties using the CVD process, a relatively high substrate temperature is usually required $\left(>200{ }^{\circ} \mathrm{C}\right)$. Therefore, the materials that can (a)

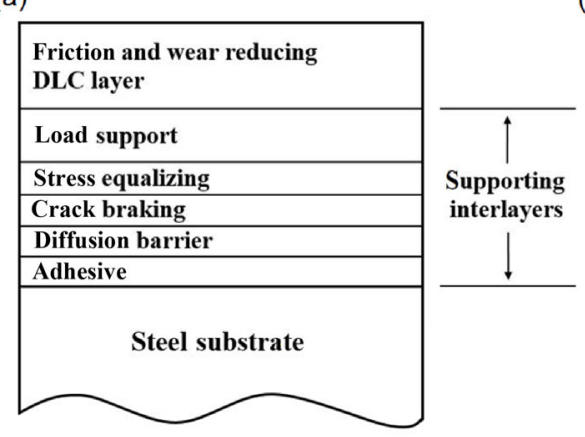

(b)

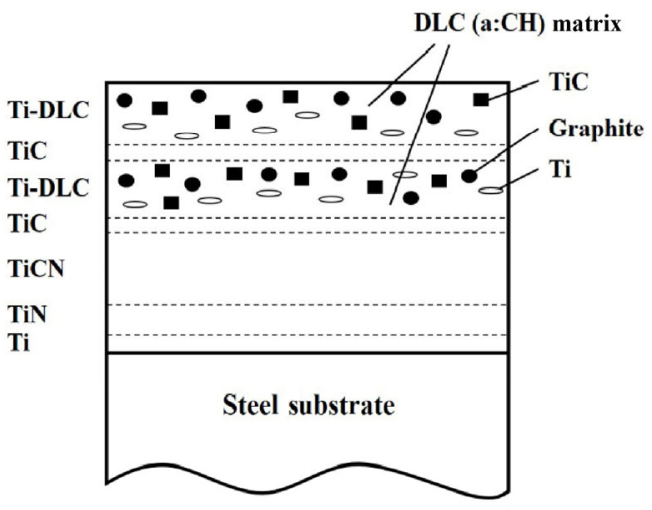

Fig. 3 (a) Schematic representation of individual layers and their functionality in a multilayer coating system. (b) Example of a functional multilayer coating developed for steel surface protection against wear. Adopted from Ref. [7], with permission from Elsevier. 
be used as substrate in the CVD process are limited because their properties can be altered at elevated temperatures in some cases (e.g., polymers and some metals). There are also some studies have reported using a combination of both CVD and PVD processes to fabricate multilayer coatings [30, 31].

DLC, which is one of the most common materials used in multilayer coating systems, can be deposited using both CVD and PVD techniques. In the CVD process, methane $\left(\mathrm{CH}_{4}\right)$ gas is usually used as the carbon source that results in the incorporation of hydrogen atoms in the DLC structure during growth (known as hydrogenated DLC). Hydrogenated DLCs are rich in $\mathrm{sp}^{2}$ hybrids with a relatively low percentage of $\mathrm{sp}^{3}$ hybrids (less than $40 \%$ ), which in turn leads to a lower hardness (lower than $20 \mathrm{GPa}$ ). Moreover, deposition of DLC coatings using the CVD method can result in a rough polycrystalline structure which lowers the transparency compared to that of DLCs with an amorphous structure. Therefore, DLC coatings fabricated by the CVD method are often not suitable for optical device applications [12, 32].

The drawbacks mentioned above regarding the CVD method can be overcome by using PVD-based deposition techniques. In PVD processes, the coating is deposited by condensation from a flux of neutral or ionized metal atoms in a vacuum environment [27]. Several PVD techniques can be used for deposition of hard coatings. Among them, ion plating and sputtering processes are the most common PVD processes for the deposition of DLC (or multilayers in general). Each of these PVD processes has its unique features regarding the type of evaporation of the metallic components and plasma conditions during the deposition process. In the case of ion plating, evaporation takes place by a high-energy arc that quickly moves over a spot on the metal surface to be evaporated. The plasma generated consists of highly ionized metal vapor [32]. In the case of sputtering, atoms are ejected from a target by the impact of inert gas ions or energetic neutral atoms. Ion plating generally requires a higher energy input than the PVD sputtering process. Table 1 summarizes the characteristics and parameters of PVD-based deposition techniques [27].

Ion plating-based techniques are typically used to deposit hard coatings because of the high ion energy and high ionization rate. However, the relatively large particles formed during the arc evaporation may lead to degradation of the coating properties [33]. Taking into account all the characteristics of the different PVD processes, PVD techniques based on sputtering is considered to be the suitable technique for multilayer coating fabrication [6].

Sputtering processes allow precise control of the deposition parameters. Therefore, properties of the coatings (e.g., residual stress, hardness, morphology, etc.) being deposited can be readily adjusted to obtain the optimum properties for tribological applications. Li et al. [34] studied the effect of controlling the deposition parameters on the properties of multilayer coatings. A DLC multilayer coating was produced by controlling the negative applied bias during deposition. It was shown that the residual stress significantly increased from approximately 2 to $7 \mathrm{GPa}$ as the negative bias voltage increased from -70 to $-200 \mathrm{~V}$ (Fig. 4(a)). The hardness also increased slightly from approximately 19 to $21 \mathrm{GPa}$ (Fig. 4(b)). Thus, drastic variation in the residual stress and hardness could be achieved by tuning the negative bias voltage during the deposition process.

Table 1 Typical characteristics and parameters of PVD-based deposition techniques. Reprinted from Ref. [27], with permission from Elsevier.

\begin{tabular}{ccccc}
\hline Parameters & \multicolumn{4}{c}{ Processes } \\
\hline & Magnetron sputtering & Anodic arc ion plating & Electron beam ion plating & Cathodic arc ion plating \\
Evaporation tool & Sputter effect & Electron beam & Electron beam & Thermal arc \\
Phase transformation & Solid-vapor & Solid-vapor & Liquid-vapor & Solid-vapor \\
Target geometry & Flexible & Limited & Limited & Flexible \\
Target ionization (\%) & $1-5$ & $5-40$ & $<1$ & $50-100$ \\
Additional ionization & Aimed & Unusual & Aimed & Not necessary \\
Inert gasses necessary & Yes & No & Variable & No \\
\hline Reactive deposition & Yes & Yes & Yes & Yes \\
\hline
\end{tabular}


(a)

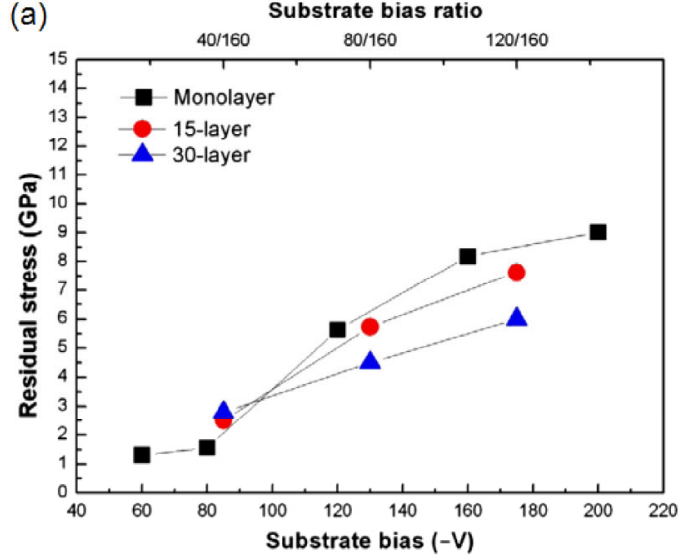

(b)

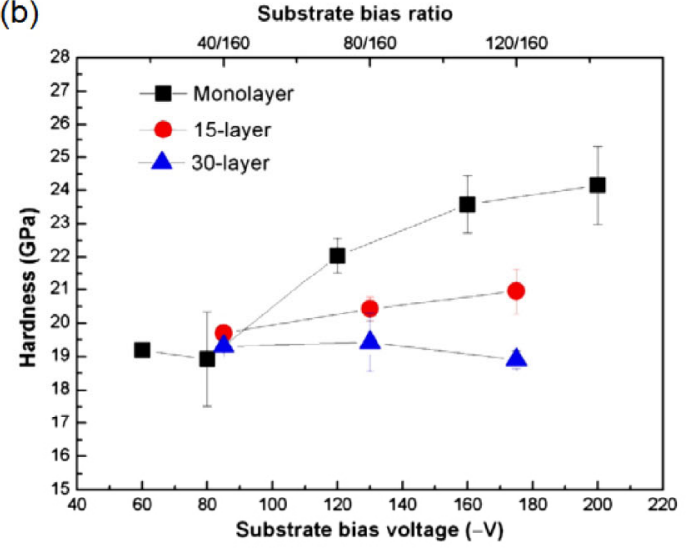

Fig. 4 (a) Residual stress and (b) hardness of coatings as a function of substrate bias and substrate bias ratio. Reprinted from Ref. [34], with permission from Elsevier.

Paulitsch et al. [35] showed that power source used for deposition can greatly influence the tribologial properties of the coatings. As given in Table 1, magnetron sputtering has a low ionization degree that often results in the formation of porous and underdense films with a high defect density if deposited at room temperature [36]. To overcome this problem, the conventional DC magnetron sputtering process was combined with high power impulse magnetron sputtering (HIPIMS) to deposit a CrN/TiN multilayer coating. HIPIMS allows a much greater metal-ion and plasma density, and thus, a higher ion to neutral sputtered species ratio due to the high-power dissipation can be delivered to the target (ionization rate above $40 \%$ ) [37]. As a result, the HIPIMS process is beneficial for tailoring the morphology and structure of the coating. Experimental results demonstrated that the COF could be lowered significantly from 0.25 to 0.05 when an additional HIPIMS cathode equipped with a $\mathrm{Cr}$ or $\mathrm{Ti}$ target material was added to the process. Wang et al. [38] investigated the correlations between target power and Ar gas pressure on the characteristics W-Cu multilayer coatings. It was shown that a more dense coating could be deposited at a low Ar pressure and high power. Moreover, strong coating adhesion correlated well with dense layers and fine grain structure.

All the studies mentioned above showed that sputtering parameters significantly affect the structural, mechanical, and thus, the tribological properties of the coatings. In this regard, considering the desired material properties and target application is a major step prior to deciding the deposition method.

\section{Friction and wear characteristics}

The friction and wear characteristics, together with the mechanical properties of multilayer coatings fabricated using a wide range of materials were investigated. Considering the types of multilayer coatings with respect to the main element used in the coatings, the coatings were divided into three groups, namely Ti-based, Cr-based, and other materials. $\mathrm{Ti}$ and $\mathrm{Cr}$ are commonly used interlayers utilized as adhesion layers prior to deposition of the main multilayer coating on metal substrates. Ti and $\mathrm{Cr}$ are excellent adhesion layers because of their high binding energy that can readily form oxides, nitrides or carbides with adjacent layers. However, their effect on the performance and tribological characteristics of multilayer coatings strongly depends on their structure (e.g., polycrystalline or amorphous). Each structure can have its advantages or disadvantages, and therefore, should be decided carefully depending on the design strategy of the multilayer coating. For example, in a previous research where design of a multilayer coating with high degree of elasticity was desired, it was found that amorphous materials exhibited higher elasticity compared with their polycrystalline counterparts [3].

Despite the large number of combination of materials reported in the literature for multilayer coatings, they mostly follow a logical and established principle that 
imposes a low friction and hard material as the top surface layer (e.g., DLC, $W_{2}$, etc.). While the bottom layers should provide sufficient support in terms of adhesion, hardness, ductility and elasticity to increase the overall coating stability, the upper layer should have low friction properties to minimize the generation of frictional energy that can be used to damage the surface layer. However, even after removal of the upper layers, the multilayer coating can still maintain its anti-wear properties because periodical alternation of such materials allows effective prevention of crack deflection and propagation, which is one of the major failure modes of coatings [20,39]. Considering these factors, a desirable multilayer structure would be a coating that provides low friction at the surface with high shear strength and adequate elasticity within the coating layers [3].

\subsection{Ti-based multilayer coatings}

As mentioned previously, enormous attention has been devoted to Ti and Ti-alloys as potential candidates to be used in multilayer coatings for tribological applications. In one of the earlier works, Deng and Braun [16] fabricated a multilayer system with a $\mathrm{Ti} / \mathrm{TiN} / \mathrm{TiCN} / \mathrm{TiC} / \mathrm{DLC}$ sequence using magnetron sputtering to improve the friction and wear properties of AISI 420 steel. A maximum hardness of 39 GPa and a minimum stable COF of $\sim 0.25$ could be achieved (counterpart: $6 \mathrm{~mm} \mathrm{Al} \mathrm{O}_{3}$ ceramic ball; load: $100 \mathrm{gf}$ ). Shortly thereafter, Voevodin et al. [24] attempted a more complex multilayer structure: (Ti/TiC/DLC/(Ti/DLC) $)_{\times 20}$ ) and $\left(\mathrm{Ti} / \mathrm{TiC} / \mathrm{DLC} /(\mathrm{TiC} / \mathrm{DLC})_{\times 20}\right)$. The TiC/DLC combination showed a higher hardness $(30 \mathrm{GPa})$ than Ti/DLC (20 GPa) and a wear rate of about $10^{-10} \mathrm{~mm}^{3} /(\mathrm{N} \cdot \mathrm{mm})$ could be obtained. The minimum COF values against sapphire and steel counterparts (10 mm; load: $10 \mathrm{~N}$ ) were approximately 0.09 and 0.2 , respectively. Ogletree and Monterio [39] demonstrated the effectiveness of DLC/TiC multilayer coating to reduce the friction of AISI 01 tool steel. The number and thickness of layers within the films were varied while the total thickness was made to be approximately constant. A minimum COF of $\sim 0.15$ was achieved (counterpart: $6.25 \mathrm{~mm} \mathrm{Al} \mathrm{O}_{3}$ ceramic ball; load: 2 and $5 \mathrm{~N}$ ). Su and Kao [20] performed an optimization study on multilayers with TiN/Ti/TiN and TiN/TiCN/TiN sequences. Experimental results indicated that a coating with a total thickness of $7 \mu \mathrm{m}$ and layer sequence of $\mathrm{TiN} / \mathrm{TiCN} / \mathrm{TiN}$ exhibited good wear resistance. The TiN/Ti/TiN sequence, despite a higher hardness value, showed a lower wear resistance. A minimum COF of 0.1 in the lubrication condition was achieved (counterpart: steel ball). The potential of TiN/TiCN sequence for friction and wear reduction was further investigated by Zheng et al. [40]. A maximum hardness and minimum wear rate of $34 \mathrm{GPa}$ and $1.15 \times$ $10^{-9} \mathrm{~mm}^{3} /(\mathrm{N} \cdot \mathrm{mm})$, respectively, were obtained. The coating showed different $\mathrm{COF}$ values of 0.12 and 0.65 when slid against $3 \mathrm{~mm} \mathrm{Si}_{3} \mathrm{~N}_{4}$ ceramic ball and steel ball counterparts (load: $1 \mathrm{~N}$ ), respectively. At elevated temperature $\left(550{ }^{\circ} \mathrm{C}\right)$, Bao et al. [22] studied the tribological behavior of $\mathrm{TiCN} / \mathrm{TiC} / \mathrm{TiN}$ multilayer coatings deposited by CVD on high-speed steel substrates. The coating showed a relatively high COF (0.6) and wear rate $\left(7.3 \times 10^{-9} \mathrm{~mm}^{3} /(\mathrm{N} \cdot \mathrm{mm})\right)$ at $550{ }^{\circ} \mathrm{C}$ against a $5 \mathrm{~mm}$ WC ceramic ball under $20 \mathrm{~N}$ in comparison to the COF and wear rate obtained at room temperature $\left(0.5\right.$ and $5.3 \times 10^{-10} \mathrm{~mm}^{3} /(\mathrm{N} \cdot \mathrm{mm})$, respectively).

Cheng et al. [33] performed a comprehensive study on the mechanical and tribological behavior of TiN/Ti multilayer coatings. Multilayers with a fixed TiN layer thickness and different $\mathrm{Ti}$ layer thicknesses were deposited by using a filtered arc deposition technique. The results revealed that increasing the $\mathrm{Ti}$ layer thickness from 0 to $150 \mathrm{~nm}$ lowered the hardness (from 32 to $16 \mathrm{GPa}$ ) and wear resistance, significantly. A minimum wear rate and COF of $\sim 2 \times 10^{-9} \mathrm{~mm}^{3} /(\mathrm{N} \cdot \mathrm{mm})$ and $\sim 0.6$ (counterpart: $6 \mathrm{~mm} \mathrm{Al}_{2} \mathrm{O}_{3}$ ceramic ball; load: $1 \mathrm{~N})$, respectively, were achieved. By adding a DLC layer on the top and reversing the deposition sequence of TiN and Ti (Ti/TiN/DLC), Liu et al. [41] and Kot et al. [42] tried to improve the friction and wear behavior of steel substrates. A minimum wear rate of approximately $1.2 \times 10^{-9} \mathrm{~mm}^{3} /(\mathrm{N} \cdot \mathrm{mm})$ under $5 \mathrm{~N}$ was obtained [42]. The multilayer coatings showed maximum hardness values of $32 \mathrm{GPa}$ and $20 \mathrm{GPa}$ and the minimum COF values of 0.25 and 0.15 , respectively (counterparts: $4 \mathrm{~mm}$ steel ball and $6 \mathrm{~mm}$ $\mathrm{Al}_{2} \mathrm{O}_{3}$ ceramic ball). Al-Bukhaiti et al. [43] assessed the effects of normal load and sliding speed on the friction and wear behavior of $[\mathrm{Ti} / \mathrm{TiAlN} / \mathrm{TiAlCN}]_{5}$ 
multilayer coatings with addition of $\mathrm{Al}$ deposited on AISI H11 steel using magnetron sputtering. The coatings showed a maximum hardness of $20 \mathrm{GPa}$. The lowest COF and wear rate were 0.25 and $\sim 3 \times$ $10^{-9} \mathrm{~mm}^{3} /(\mathrm{N} \cdot \mathrm{mm})$, respectively (counterpart: $6 \mathrm{~mm}$ $\mathrm{Al}_{2} \mathrm{O}_{3}$ ceramic ball, load: 2-10 N). Chu and Shen [44] investigated the tribological behavior of TiN/TiBN multilayer films with different bilayer thicknesses (from 1.4 to $9.7 \mathrm{~nm}$ ) deposited on Si and AISI M42 tool steel. The mechanical and tribological properties of multilayer coatings were found to be closely related to the bilayer thickness. For the bilayer thickness of $1.8 \mathrm{~nm}$, a maximum hardness of $\sim 29.5 \mathrm{GPa}$ was achieved and a minimum COF of 0.5 was obtained (counterpart: WC ceramic ball; load: $5 \mathrm{~N}$ ). Zhang et al. [45] deposited $\mathrm{Ti}(\mathrm{C}, \mathrm{N})$ multilayer coatings by magnetron sputtering on $\mathrm{Si}$ and assessed their hardness and COF with respect to the current fed through the graphite target. As the current increased from 0.3 to $1.8 \mathrm{~A}$, the hardness increased initially (maximum hardness of $\sim 45 \mathrm{GPa}$ at $0.9 \mathrm{~A}$ ) and then decreased gradually. As a result, the COF monotonically decreased down to a constant value of approximately 0.2 (counterpart: WC ceramic ball; load: $6 \mathrm{~N}$ ). Liu et al. [46] investigated the tribological and mechanical properties of TiN/CN $\mathrm{CN}_{x}$ multilayer coatings deposited by magnetron sputtering. The hardness of the coatings varied from 12.5 to $31 \mathrm{GPa}$ with respect to the bilayer thickness (from 4.2 to $40.3 \mathrm{~nm}$ ). The multilayer coating with a bilayer thickness of $4.2 \mathrm{~nm}$ showed the highest

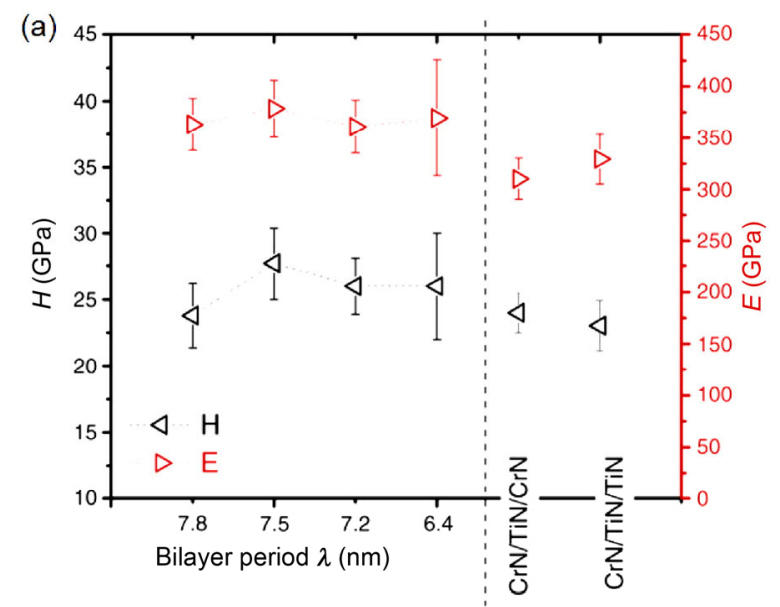

hardness and the lowest $\mathrm{COF}$ and wear rate $(0.12$ and $7 \times 10^{-11} \mathrm{~mm}^{3} /(\mathrm{N} \cdot \mathrm{mm})$, respectively) against a $3 \mathrm{~mm}$ $\mathrm{Si}_{3} \mathrm{~N}_{4}$ ball counterpart under $5 \mathrm{~N}$ applied load. Kumar et al. [47] fabricated and compared various TiC-metal carbide-based multilayers $(\mathrm{ZrC}, \mathrm{CrC}$, and $\mathrm{WC})$ deposited on 316LN steel by magnetron sputtering. Experimental results revealed the poor crystalline nature of the $\mathrm{TiC} / \mathrm{CrC}$ multilayer, which was postulated to be the reason for the relatively low hardness and wear resistance. The $\mathrm{TiC} / \mathrm{ZrC}$ multilayer showed the highest hardness ( $30 \mathrm{GPa})$ and the best tribological performance among the coatings with a minimum COF of 0.43 and a wear rate of $2.1 \times 10^{-11} \mathrm{~mm}^{3} /(\mathrm{N} \cdot \mathrm{mm})$ (counterpart: $6 \mathrm{~mm}$ steel ball, load: $1 \mathrm{~N}$ ).

Multilayer coatings consisting of both Ti-based and Cr-based nitrides were also developed [35]. This study showed that the $\mathrm{CrN} / \mathrm{TiN}$ multilayer coatings were effective in reducing the $\mathrm{COF}$ of bare steel from 0.7 to 0.35 (H-25 GPa, modulus-375 GPa) (Fig. 5(a)) by decreasing the bilayer thickness from 7.8 to $6.4 \mathrm{~nm}$ while keeping the $\mathrm{CrN}$ layer thickness constant at $3.2 \mathrm{~nm}$. It should be noted that a further reduction of the COF at room temperature dry sliding condition to approximately 0.25 or 0.05 (counterpart: $6 \mathrm{~mm} \mathrm{Al}_{2} \mathrm{O}_{3}$ ceramic ball; load: $1 \mathrm{~N}$ ) could be obtained when Ti and Cr were deposited by an HIPIMS cathode (Fig. 5(b)).

\subsection{Cr-based multilayer coatings}

Numerous multilayer coatings based on $\mathrm{Cr}$ have also been developed. Yang and Teer [18] demonstrated

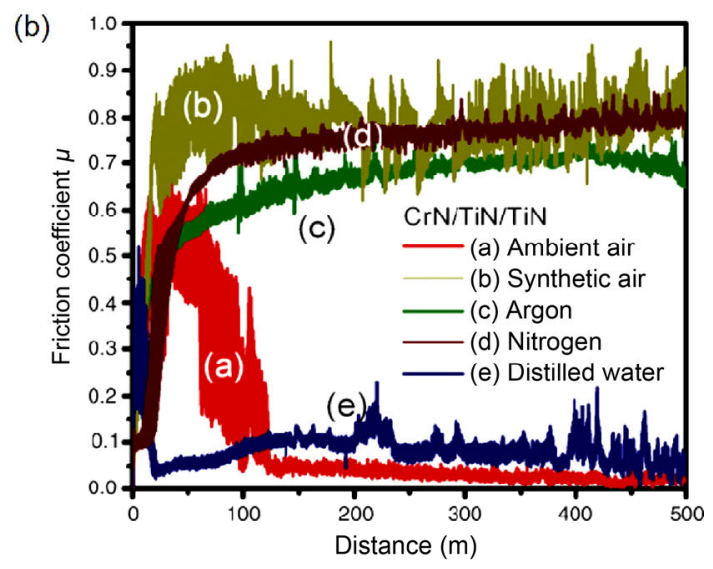

Fig. 5 (a) Hardness $(H)$ and Young's modulus $(E)$ of multilayer coatings with respect to bilayer thickness (right side of the dash-line: multilayers with additional CrN and TiN layer deposited by HIPIMS) and (b) COF of coatings obtained in different atmospheres. Reprinted from Ref. [35], with permission from Elsevier. 
the superiority of $\mathrm{C} / \mathrm{Cr}$ multilayer coated drills to those of commercial TiN coated drills. $\mathrm{C} / \mathrm{Cr}$ multilayer coatings showed a wear rate of $2 \times 10^{-11} \mathrm{~mm}^{3} /(\mathrm{N} \cdot \mathrm{mm})$, which was three times lower than that of the TiN coated drills, and a minimum COF of 0.05 was achieved (counterpart: $5 \mathrm{~mm}$ WC ceramic ball; load: 10-80 N). Gilewicz et al. [48, 49] used a cathodic arc evaporation method to deposit a $\mathrm{Cr} / \mathrm{CrCN}$ multilayer on steel. A $0.1 \mu \mathrm{m} C r$ layer was used as a sublayer. The wear tests against $10 \mathrm{~mm} \mathrm{Al}_{2} \mathrm{O}_{3}$ ceramic balls revealed that the wear resistance of the multilayer coating was lower than that of $\mathrm{Cr}$ or $\mathrm{CrCN}$ single layers. A minimum COF of $\sim 0.4$ was achieved (load: $30 \mathrm{~N}$ ). Beliardouh et al. [50] fabricated different multilayers composed of $\mathrm{Cr}, \mathrm{CrN}$, and CrAlN on AISI 4140 steel substrates using radio frequency ( $R F)$ magnetron sputtering technique. The multilayer with the sequence of $[\mathrm{Cr}$ (45 nm)/CrN (106 nm)/CrAlN (150 nm)] showed the highest hardness (32 GPa) and wear resistance. A minimum $\mathrm{COF}$ of 0.4 against a $6 \mathrm{~mm} \mathrm{Al}_{2} \mathrm{O}_{3}$ ceramic ball under $1 \mathrm{~N}$ was achieved.

Vyas et al. [51] performed a fundamental study on the frictional behavior of $\mathrm{CrN} / \mathrm{CN}_{x}$ nano-scale multilayer coatings deposited on $\mathrm{Si}$ and high speed steel (HSS) by magnetron sputtering. The effects of negative substrate bias voltage and bilayer thickness on the structural and frictional properties were assessed. A maximum hardness of $\sim 36 \mathrm{GPa}$ and a minimum COF of $\sim 0.4$ at $140 \mathrm{~V}$ were achieved (load: $10 \mathrm{~N}$ ). In another study performed by Bayon et al. [52], the tribo-corrosion property of $\mathrm{Cr} / \mathrm{CrN}$ multilayer coatings deposited by the cathodic arc method on steel and silicon substrates was investigated. A maximum hardness of $\sim 29 \mathrm{GPa}$ and a minimum COF of $\sim 0.3$ was achieved (counterpart: $4 \mathrm{~mm} \mathrm{Si}_{3} \mathrm{~N}_{4}$ ball). A more complex system was synthesized by Shi et al. [53] by nitriding of $\mathrm{Cr}$, $\mathrm{Ti}$, and $\mathrm{Al}(\mathrm{CrN} / \mathrm{TiN} / \mathrm{CrN} / \mathrm{AlN})$ on a $\mathrm{Mg}$ alloy substrate using a magnetron sputtering ion plating system at different bias voltages (ranging from -40 to $-90 \mathrm{~V}$ ). The coating deposited at $-50 \mathrm{~V}$ showed the lowest COF of $\sim 0.25$ (counterpart: $\mathrm{Si}_{3} \mathrm{~N}_{4}$ ball). Gilewicz and Warcholinski [54] improved the tribological properties of a HS6-5-2 steel substrate using a $\mathrm{Mo}_{2} \mathrm{~N} / \mathrm{CrN}$ multilayer coating. The multilayer coating showed a hardness above $25 \mathrm{GPa}$ and a lower $\mathrm{COF}$ and wear rate than those of the single layer $\mathrm{CrN}$ coating. A minimum $\mathrm{COF}$ and wear rate of 0.4 and $9 \times 10^{-11} \mathrm{~mm}^{3} /\left(\mathrm{N} \cdot \mathrm{mm}\right.$ ) (counterpart: $10 \mathrm{~mm} \mathrm{Al}_{2} \mathrm{O}_{3}$ ball; load: $30 \mathrm{~N}$ ) were achieved, respectively.

\subsection{Other materials}

A variety of materials other than Ti-based and Cr-based materials have been employed to design and fabricate multilayer coatings. As for metal/metal-based multilayer coatings, Ghosh et al. [55] deposited [Ni $(4.5 \mathrm{~nm} / \mathrm{Cu}$ $(2,4$, and $8 \mathrm{~nm})]$ multilayer coatings on a stainless steel (AISI SS 304) substrate. The multilayer coating with the minimum $\mathrm{Cu}$ thickness showed the lowest COF and wear rate of $\sim 0.4$ and $1.3 \times 10^{-7} \mathrm{~mm}^{3} /(\mathrm{N} \cdot \mathrm{mm})$, respectively (counterpart: $6 \mathrm{~mm}$ WC ceramic ball; load: 3-11 N). Detailed investigation of the wear scar morphology, as well as wear rate measurement, revealed the significant dependence of the wear mechanism to the applied normal load. At low loads, the $H / E$ ratio and residual stress governed the wear rate, and the principle wear mode was abrasive. At moderate loads, the role of residual stress became insignificant while wear was governed by the $H / E$ ratio and plastic deformation. However, at higher loads, plastic deformation played a major role in dictating the wear behavior. Miki et al. [30] fabricated DLC/ W-based multilayer coatings using RF CVD and magnetron sputtering on $\mathrm{Si}$ and studied their frictional behavior under $\mathrm{N}_{2}$ atmosphere. A minimum COF of $\sim 0.1$ was achieved (counterpart: $6 \mathrm{~mm}$ steel ball; load: $1 \mathrm{~N}$ ).

Gayathri et al. [56] performed a comprehensive study on the tribological properties of DLC in combination with various transition metals $(\mathrm{Cr}, \mathrm{Ag}, \mathrm{Ti}$, and $\mathrm{Ni}$ ) in the form of periodical multilayers deposited by a pulsed laser. DLC/Ni and DLC/Ti multilayer coatings showed the lowest COF of 0.1 and the highest wear resistance among the coated specimens. However, the hardness values turned out to be quite similar (9-11 GPa) for all the coated specimens. Detailed analysis revealed the formation of a tribofilm, which was believed to be responsible for the relatively low wear in the case of DLC/Ni and DLC/Ti multilayer coatings (counterpart: $6 \mathrm{~mm}$ steel ball; load: $1 \mathrm{~N}$ ). Kilman et al. [31] utilized $\mathrm{Al}$ in hydrogenated amorphous carbon (a-C:H:Al) to fabricate a multilayer coating on AISI M2 high-speed steel. It was found that even 
though the inclusion of $\mathrm{Al}$ lowered the mean hardness value compared to pure a-C:H coatings, the frictional behavior was improved. The COF decreased from approximately 0.2 to 0.1 when slid against a $6 \mathrm{~mm}$ steel ball under an applied load of $10 \mathrm{~N}$.

Liu et al. [57] deposited carbon nitride $\left(\mathrm{CN}_{x} / \mathrm{CN}_{x}\right)$ multilayers with sequential $\mathrm{sp}^{3}$-rich $\left(54 \% \mathrm{sp}^{3}\right)$ and $\mathrm{sp}^{2}$-rich $\left(26 \% \mathrm{sp}^{3}\right)$ layers on $\mathrm{Si}$ using magnetron sputtering technique. The multilayer coating showed a lower compressive stress (approximately 60\% lower) and a higher hardness than the individual layers. A minimum COF of $\sim 0.1$ and maximum hardness of $\sim 30$ GPa could be achieved. In a more comprehensive study, a similar concept was applied to DLC multilayer coatings consisting of $\mathrm{sp}^{2}$-rich (soft DLC) and $\mathrm{sp}^{3}$-rich (hard DLC) phases with different thickness ratios (hard DLC/soft DLC: 2:1, 1:1, 1:2) [58]. The coatings were deposited using the filtered cathodic vacuum arc (FCVA) method on Si and Ti-6Al-4V alloy substrates. The hardness of the coatings varied from $\sim 14$ to $\sim 24 \mathrm{GPa}$ depending on the modulation ratio. It was found that the multilayer DLC coatings with different modulation ratios could effectively decrease the residual stress of monolithic hard DLC coatings (Fig. 6). The experimental results showed that the multilayer coating with 1:1 thickness ratio resulted in the best wear resistance due to a balance between hardness and residual stress.

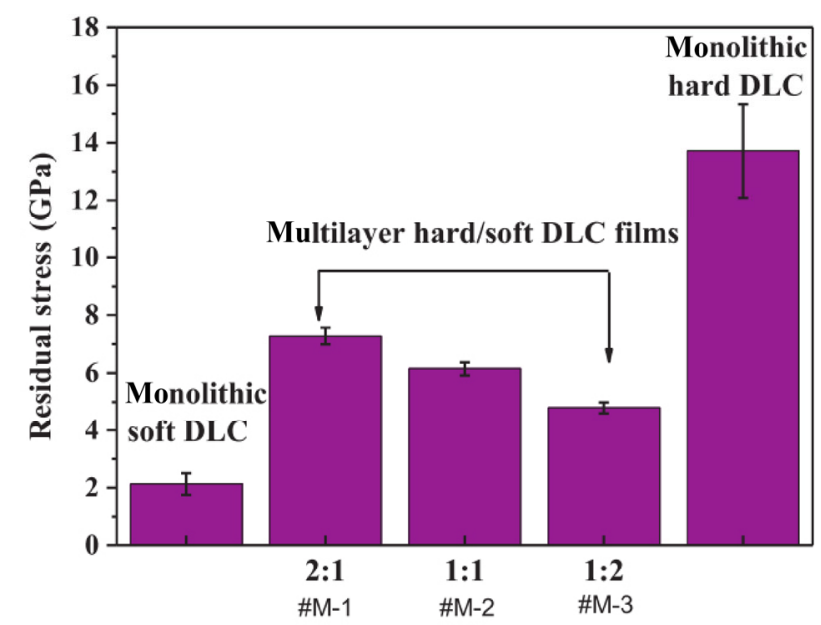

Fig. 6 Residual stress for the monolithic DLC and multilayer DLC coatings with respect to modulation ratios. (a) \#M-1 (modulation ratio is 2:1), (b) \#M-2 (modulation ratio is $1: 1$ ), (c) \#M-3 (modulation ratio is 1:2). Reprinted from Ref. [58], with permission from Elsevier.
Bewilgua et al. [59] investigated the tribological properties of a carbon-based multilayer coating (a-C:H/a-C:H:Si:O and a-C:H/a-C:H:Si) fabricated by plasma assisted chemical vapor deposition (PACVD) using methane $\left(\mathrm{CH}_{4}\right)$, hexamethyldisiloxane (HMDSO) and tetramethylsilane (TMS) as precursors. Using this combination, a maximum hardness of approximately $23 \mathrm{GPa}$ and a minimum COF of 0.1 was achieved (counterpart: steel ball). Liu et al. [60] developed a multilayer structure composed of WC and C periodic coatings fabricated by sputtering technique. A maximum hardness of $\sim 14 \mathrm{GPa}$ was achieved. The coatings were prepared with two different top layers (WC and C) and sliding tests against a steel counterpart were performed. The multilayer coating with WC top layer showed a higher COF and wear rate when compared to those of coatings with $C$ top layer. A minimum COF of $\sim 0.1$ was achieved (load: 0.2-0.9 N). Braic et al. [61] prepared a $\mathrm{TiSiC} / \mathrm{NiC}$ multilayer coating by a cathodic arc in a $\mathrm{CH}_{4}$ atmosphere and studied the effects of bilayer thickness ranging from 2.5 to $19.8 \mathrm{~nm}$ on their friction and wear behavior. The best tribological characteristics were obtained for the multilayer coating with a bilayer thickness of $4.8 \mathrm{~nm}$. The coatings showed hardness values ranging from $19-26 \mathrm{GPa}$ and the minimum COF and wear rates were 0.16 and $2.9 \times$ $10^{-7}\left(\mathrm{~mm}^{3} /(\mathrm{N} \cdot \mathrm{mm})\right)$, respectively (counterpart: $6 \mathrm{~mm}$ sapphire ball; load: $3 \mathrm{~N}$ ). Braic et al. [62] also investigated the structural and tribological properties of $\mathrm{Zr} / \mathrm{ZrCN}$ multilayer coatings (bilayer thickness: 4.4 to $70 \mathrm{~nm}$ ) deposited on M2 steel and Si substrates using cathodic arc technique. The coatings showed a maximum hardness of $\sim 28 \mathrm{GPa}$. Multilayer coatings with a bilayer thickness of $13 \mathrm{~nm}$ exhibited a minimum COF and wear rate of 0.2 and $2 \times 10^{-9} \mathrm{~mm}^{3} /(\mathrm{N} \cdot \mathrm{mm})$, respectively (counterpart: $6 \mathrm{~mm}$ sapphire ball; load: $3 \mathrm{~N})$. Ge et al. [63] employed a different strategy using $\mathrm{VC} / \mathrm{Ni}$ multilayer coatings to improve the wear resistance of M2 tool steel. The coatings exhibited wear rates in the order of $10^{-9} \mathrm{~mm}^{3} /(\mathrm{N} \cdot \mathrm{mm})$, which was one order of magnitude lower than that of bare tool steel. A maximum hardness of $\sim 18 \mathrm{GPa}$ and a minimum COF of $\sim 0.6$ was achieved (counterpart: $6 \mathrm{~mm} \mathrm{Al}_{2} \mathrm{O}_{3}$ ball; load: $1 \mathrm{~N}$ ).

Penkov et al. [3] reported on the development of a novel functional coating that was comprised of 

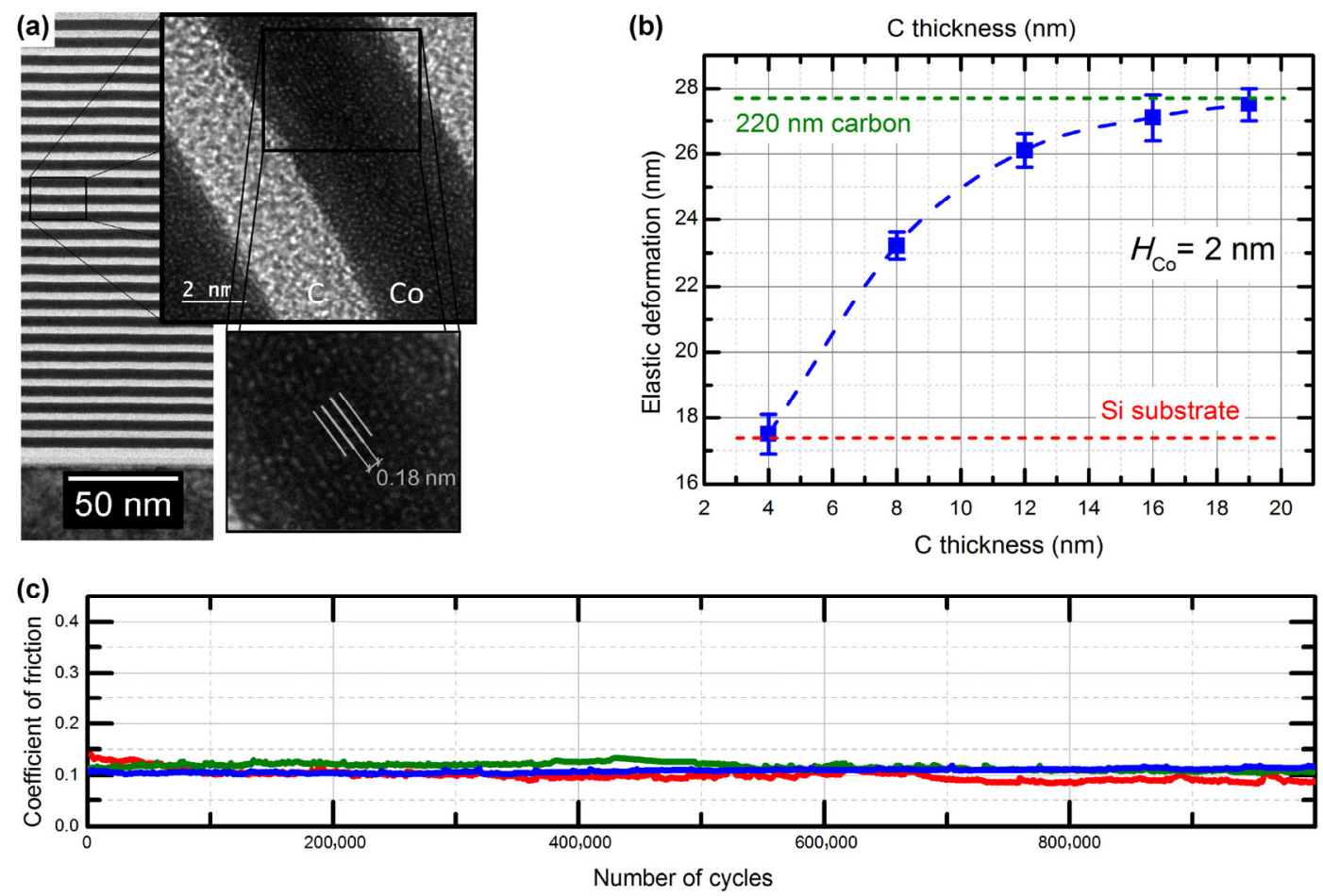

Fig. 7 (a) Cross-sectional TEM images cobalt/carbon multilayer coating. (b) Elastic deformation of the multilayer coatings as a function of the carbon thickness for a fixed cobalt thickness of $2 \mathrm{~nm}$. (c) Friction coefficient as a function of the sliding distance for three repeated tests. Reprinted from Ref. [27], with permission from ACS publication.

alternating nanolayers of amorphous carbon and cobalt that exhibited extraordinarily high micro- and macro-scale wear resistance in ordinary atmospheric condition. Multilayers with various thicknesses of amorphous carbon $(4,8,12,16$, and $19 \mathrm{~nm})$ and cobalt (1.5 to $5.6 \mathrm{~nm}$ ) were deposited to identify the optimum structure to obtain the minimum COF and wear rate (Fig. 7(a)). Co was selected as the pair material for amorphous carbon based on the following criteria: limited intermixing with carbon, formation of an amorphous structure, the ability to form a nanometerthick continuous layer by sputtering, and a high hardness and Young's modulus [64]. A minimum wear rate of $3 \times 10^{-13} \mathrm{~mm}^{3} /(\mathrm{N} \cdot \mathrm{mm})$ was obtained that was 8-10-fold lower than that of the lowest previously reported value (counterpart: $1 \mathrm{~mm}$ steel ball; load: $3 \mathrm{gf}$ ). Such a low wear rate could be achieved because of the unique structure of the multilayer coatings that simultaneously provided high elasticity and ultrahigh shear strength (Fig. 7(b)). The coatings showed a COF of 0.1 , which remained stable for more than one million cycles (Fig. 7(c)).
As for a polymer-based multilayer coating, $\mathrm{Ou}$ et al. [65] successfully fabricated a polydopamine (PDA)/grapheme oxide (GO) multilayer coating on a Si substrate using a layer by layer self-assembling process. The experimental results showed that the coatings improved the frictional behavior (COF: 0.18) significantly when compared with the bare substrate (counterpart: $3 \mathrm{~mm}$ steel ball; load: 0.5-1 N). Besides this work, multilayer coatings based on polymeric materials could not be found.

\section{Summary}

The status and properties of multilayer coating systems for tribological applications were reviewed. Special attention was given to materials, design concepts, mechanical properties, deposition method, and friction and wear characteristics of these types of coatings. Based on the extensive literature surveyed, it may be stated that multilayer coatings offer the means to tailor the surface properties of mechanical components to attain the properties in demand. The primary design 
parameters for multilayer coatings are material selection, number of layers, thickness of individual layers, interlayer type and microstructures of the layers [6].

It should be noted that classification of the tribological properties of different multilayer coating systems is not straightforward due to their system and material dependencies. Friction and wear are not only dependent on the materials, but also on the deposition method and parameters together with the properties of the counter body [66]. Given the wide spectrum of materials and methods used to fabricate multilayer coatings for tribological applications, the most relevant works may be summarized as shown in Table 2.

By selecting the proper combination of materials and design strategy, multilayer coatings can be adapted to reduce friction and increase wear resistance of mechanical components in a variety of tribological applications. Because of high level of flexibility in multilayer coating systems with respect to design variables, there is still much room for further optimization of these types of coatings [67]. With further effort in identifying the effects of numerous process parameters in the fabrication and design of multilayer coatings on their tribological properties, better coating systems with superior functionality are expected to be achieved.
Open Access: The articles published in this journal are distributed under the terms of the Creative Commons Attribution 4.0 International License (http:// creativecommons.org/licenses/by/4.0/), which permits unrestricted use, distribution, and reproduction in any medium, provided you give appropriate credit to the original author(s) and the source, provide a link to the Creative Commons license, and indicate if changes were made.

\section{References}

[1] Lin L, Kim D E, Kim W K, Jun S C. Friction and wear characteristics of multi-layer graphene films investigated by atomic force microscopy. Surface and Coatings Technology 205: 4864-4869 (2011)

[2] Penkov O V, Kim H J, Kim D E. Tribology of grapheme: A review. International Journal of Precision Engineering and Manufacturing (IJPEM) 15: 577-585 (2014)

[3] Penkov O V, Devizenko A Y, Khadem M, Zubarev E N, Kondratenko V V, Kim D E. Toward zero micro/macroscale wear using periodic nano-layered coatings. ACS Applied Materials and Interfaces 7: 18136-18144 (2015)

[4] Kot M, Major L, Lackner J, Rakowski W. Carbon based coatings with improved fracture and wear resistance. Innovations in Biomedical Engineering 526: 40-48 (2016)

[5] Penkov O V, Bugayev Y A, Zhuravel I, Kondratenko V V,

Table 2 Friction and wear properties of selected multilayer coatings.

\begin{tabular}{|c|c|c|c|c|c|}
\hline Materials/Ref. & Deposition method & Thickness $(\mu \mathrm{m})$ & Load $(\mathrm{N})$ & $\mathrm{COF}$ & $\begin{array}{c}\text { Wear Rate } \\
\left(\mathrm{mm}^{3} /(\mathrm{N} \cdot \mathrm{mm})\right)\end{array}$ \\
\hline $\mathrm{Ti} / \mathrm{TiC} / \mathrm{DLC} /(\mathrm{TiC} / \mathrm{DLC})_{\times 20}[24]$ & Magnetron sputtering & $3-4$ & 10 & 0.25 & $10^{-10}$ \\
\hline$(\mathrm{TiN} / \mathrm{TiCN})_{\times 10}[40]$ & Magnetron sputtering & $\sim 10$ & 1 & 0.12 & $1.15 \times 10^{-9}$ \\
\hline $\mathrm{TiCN} / \mathrm{TiC} / \mathrm{TiN}[22]$ & CVD & $5-6$ & 20 & 0.5 & $5.3 \times 10^{-10}$ \\
\hline $\mathrm{Ti} / \mathrm{TiN} /(\mathrm{TiN} / \mathrm{Ti})[33]$ & Filtered arc & 3 & 1 & 0.6 & $2 \times 10^{-9}$ \\
\hline Ti/TiN/DLC [42] & Magnetron sputtering & Variable & 5 & 0.15 & $1.2 \times 10^{-9}$ \\
\hline$[\mathrm{Ti} / \mathrm{TiAlN} / \mathrm{TiAlCN}]_{\times 5}[43]$ & Magnetron sputtering & 2.8 & $2-10$ & 0.25 & $3 \times 10^{-9}$ \\
\hline$\left(\mathrm{TiN} / \mathrm{CN}_{\mathrm{x}}\right)_{\times 12-200}[46]$ & Magnetron sputtering & 0.5 & 5 & 0.5 & $7 \times 10^{-11}$ \\
\hline$(\mathrm{TiC} / \mathrm{ZrC})_{\times 6}[47]$ & Magnetron sputtering & 2 & 1 & 0.43 & $2.1 \times 10^{-11}$ \\
\hline Carbon/Cr [18] & Magnetron sputtering & Variable & $10-80$ & 0.05 & $2 \times 10^{-11}$ \\
\hline$\left(\mathrm{Mo}_{2} \mathrm{~N} / \mathrm{CrN}\right)_{\times 6}[54]$ & Cathodic arc & $\sim 3$ & 30 & 0.4 & $9 \times 10^{-11}$ \\
\hline $\mathrm{Ni} / \mathrm{Cu}[55]$ & Electrodeposition & 10 & $3-11$ & 0.4 & $1.3 \times 10^{-7}$ \\
\hline $\mathrm{TiSiC} / \mathrm{NiC}[61]$ & Cathodic arc & 1.1 & 3 & 0.16 & $2.9 \times 10^{-7}$ \\
\hline $\mathrm{Zr} / \mathrm{ZrCN}[62]$ & Cathodic arc & 3.2 & 3 & 0.2 & $2 \times 10^{-9}$ \\
\hline VC/Ni [63] & Magnetron sputtering & $1.5-2$ & 1 & 0.6 & $10^{-9}$ \\
\hline $\mathrm{Co} / \mathrm{C}[3]$ & Magnetron sputtering & 0.2 & 0.03 & 0.1 & $3 \times 10^{-13}$ \\
\hline
\end{tabular}


Amanov A, Kim D E. Friction and wear characteristics of c/si bi-layer coatings deposited on silicon substrate by dc magnetron sputtering. Tribology Letter 48: 123-131 (2012)

[6] Holleck H, Schier V. Multilayer PVD coatings for wear protection. Surface and Coating Technology 76-77: 328336 (1995)

[7] Voevodin A A, Schneider J M, Rebholz C, Matthews A. Multilayer composite ceramic-metal-DLC coatings for sliding wear applications. Tribology International 29: 559-570 (1996)

[8] Habing K H, MeierKocker G. Possibilities of model wear testing for preselection of hard coatings for cutting tools. Surface and Coating Technology 62: 428-437 (1993)

[9] Watanabe S, Noshiro S M. Tribological characteristics of $\mathrm{WS}_{2} / \mathrm{MoS}_{2}$ solid lubricating multilayer films. Surface and Coating Technology 183: 347-351 (2004)

[10] Kim H J, Shin D G, Kim D E. Frictional behavior between silicon and steel coated with graphene oxide in dry sliding and water lubrication conditions. International Journal of Precision Engineering and Manufacturing-Green Technology (IJPEM-GT) 3: 91-97 (2016)

[11] Penkov O V, Pukha V E, Starikova S L, Khadem M, Starikov V V, Maleev M V, Kim D E. Highly wear-resistant and biocompatible carbon nanocomposite coatings for dental implants. Biomaterials 102: 130-136 (2016)

[12] Khadem M, Penkov O V, Pukha V E, Maleev M V, Kim D E. Ultra-thin nano-patterned wear-protective diamond-like carbon coatings deposited on glass using a $\mathrm{C}_{60}$ ion beam. Carbon 80: 534-543 (2014)

[13] Fan X, Xue Q, Wang L. Carbon-based solid-liquid lubricating coatings for space applications-A review. Friction 3: 191-207 (2015)

[14] Khun N W, Liu E. Tribological properties of platinum/ ruthenium/nitrogen doped diamond-like carbon thin films deposited with different negative substrate biases. Friction 2: 317-329 (2014)

[15] Subramanian C, Strafford K. Review of multicomponent and multilayer coatings for tribological applications. Wear $\mathbf{1 6 5}$ : 85-95 (1993)

[16] Deng J, Braun M. DLC multilayer coatings for wear protection. Diamond and Related Materials 4: 936-943 (1995)

[17] Wiklund U, Gunnars J, Hogmark S. Influence of residual stresses on fracture and delamination of thin hard coatings. Wear 232: 262-269 (1999)

[18] Yang S, Teer D. Investigation of sputtered carbon and carbon/ chromium multi-layered coatings. Surface and Coating Technology 131: 412-416 (2000)

[19] Su Y L, Yao S H, Leu Z L, Wei C S, Wu C T. Comparison of tribological behavior of three films-TiN, TiCN and
CrN-grown by physical vapor deposition. Wear 213: 165-174 (1997).

[20] $\mathrm{Su} \mathrm{Y,} \mathrm{Kao} \mathrm{W.} \mathrm{Optimum} \mathrm{multilayer} \mathrm{TiN-TiCN} \mathrm{coatings} \mathrm{for}$ wear resistance and actual application. Wear 223: 119-130 (1998).

[21] Huang R, Chan C, Lee C H, Gong J, Lai K H, Lee S H, Li K Y, Wen L S, Sun C. Wear-resistant multilayered diamond-like carbon coating prepared by pulse biased arc ion plating. Diamond and Related Materials 10: 1850-1854 (2001).

[22] Bao M. Xu H, Zhang H, Liu X, Tian L, Zeng Z, Song Y. Tribological behavior at elevated temperature of multilayer $\mathrm{TiCN} / \mathrm{TiC} / \mathrm{TiN}$ hard coatings produced by chemical vapor deposition. Thin Solid Film 520: 833-836 (2011)

[23] Liu H, Jiang Y, Zhou R, Tang B. Wear behaviour and rolling contact fatigue life of Ti/TiN/DLC multilayer films fabricated on bearing steel by PIIID. Vacuum 86: 848-853 (2012)

[24] Voevodin A, Walck S, Zabinski J. Architecture of multilayer nanocomposite coatings with super-hard diamond-like carbon layers for wear protection at high contact loads. Wear 203-204: 516-527 (1997)

[25] Bemporad E, Sebastiani M, Pecchio C, De Rossi S. High thickness Ti/TiN multilayer thin coatings for wear resistant applications. Surface and Coatings Technology 201: 21552165 (2006)

[26] Dekempeneer E, Van Acker K, Vercammen K, Meneve J, Neerinck D, Eufinger S, Pappaert W, Sercu M, Smeets J. Abrasion resistant low friction diamond-like multilayers. Surface and Coatings Technology 142-144: 669-673 (2001)

[27] Paldey S, Deevi S. Single layer and multilayer wear resistant coatings of (Ti,Al)N: A review. Materials Science and Engineering A 342: 58-79 (2003)

[28] Guan X, Wang Y, Zhang G, Jiang X, Wang L, Xue Q. Microstructures and properties of $\mathrm{Zr} / \mathrm{CrN}$ multilayer coatings fabricated by multi-arc ion plating. Tribology International 106: 78-87 (2017)

[29] Shugurov A R, Panin A V, Evtushenko O V, Sergeev V P, Martynyak R M. Effect of the number of layers in Zr-Y-O/ Si-Al-N multilayer coatings on their mechanical properties and wear resistance. Journal of Friction and Wear 35: 426-433 (2014)

[30] Miki H, Takeno T, Takagi T. Tribological properties of multilayer DLC/W-DLC films on Si. Thin Solid Films 516: 5414-5418 (2008)

[31] Kilman L, Jaoul C, Colas M, Tristant P, Dublanche-Tixier C, Laborde E, Meunier F, Jarry O. Friction and wear performance of multilayered a-C:H:Al coatings. Surface and Coatings Technology 284: 159-165 (2015)

[32] Robertson J. Diamond-like amorphous carbon. Materials Science and Engineering 37: 129-281 (2002) 
[33] Cheng Y, Browne T, Heckerman B, Bowman C, Gorokhovsky $\mathrm{V}$, Meletis E I. Mechanical and tribological properties of TiN/Ti multilayer coating. Surface Coatings Technology 205: 146-151 (2010)

[34] Li F, Zhang S, Kong J, Zhang Y, Zhang W. Multilayer DLC coatings via alternating bias during magnetron sputtering. Thin Solid Films 519: 4910-4916 (2011)

[35] Paulitsch J, Schenkel M, Schintlmeister A, Hutter H, Mayrhofer P H. Low friction CrN/TiN multilayer coatings prepared by a hybrid high power impulse magnetron sputtering/DC magnetron sputtering deposition technique. Thin Solid Films 518: 5553-5557 (2010)

[36] Latteman M, Ehiasarian A P, Bohlmark J, Persson P A O, Helmersson U. Investigation of high power impulse magnetron sputtering pretreated interfaces for adhesion enhancement of hard coatings on steel. Surface Coatings Technology 200: 6495-6499 (2006)

[37] Ehiasarian A P, Hovsepian P E, Hultman L, Helmerson U. Comparison of microstructure and mechanical properties of chromium nitride-based coatings deposited by high power impulse magnetron sputtering and by the combined steered cathodic arc/unbalanced magnetron technique. Thin Solid Films 457: 270-277 (2004)

[38] Wang C, Brault P, Zaepffel C, Thiault J, Pineau A, Sauvage T. Deposition and structure of $\mathrm{W}-\mathrm{Cu}$ multilayer coatings by magnetron sputtering. Journal of Physics D: Applied Physics 36: 2709-2713 (2003)

[39] Ogletree M D, Monterio O. Wear behavior of diamond-like carbon/metal carbide multilayers. Surface and Coatings Technology 108-109: 484-488 (1998)

[40] Zheng J, Hao J, Liu X, Liu W. Properties of TiN/TiCN multilayer films by direct current magnetron sputtering. Journal of Physics D: Applied Physics 45: 095303-095312 (2012)

[41] Liu H, Jiang Y, Zhou R, Tang B. Wear behaviour and rolling contact fatigue life of Ti/TiN/DLC multilayer films fabricated on bearing steel by PIIID. Vacuum 86: 848-853 (2012)

[42] Kot M, Major L, Lackner J. The tribological phenomena of a new type of TiN/a-C: H multilayer coatings. Materials and Design 51: 280-286 (2013)

[43] Al-Bukhaiti M A, Al-Hatab K A, Tillmann W, Hoffmann F, Sprute T. Tribological and mechanical properties of Ti/TiAlN/TiAlCN nanoscale multilayer PVD coatings deposited on AISI H11 hot work tool steel. Applied Surface Science 318: 180-190 (2014)

[44] Chu K, Shen Y. Mechanical and tribological properties of nanostructured TiN/TiBN multilayer films. Wear 265:

\section{6-524 (2008)}

[45] Zhang G, Li B, Jiang B, Chen D, Yan F. Microstructure and mechanical properties of multilayer $\operatorname{Ti}(\mathrm{C}, \mathrm{N})$ films by closed-field unbalanced magnetron sputtering ion plating. Journal of Materials Science and Technology 26: 119-124 (2010)

[46] Liu D, Tu J, Gu C D, Chen R, Hong C F. Tribological and mechanical behaviors of TiN/CNx multilayer films deposited by magnetron sputtering. Thin Solid Films 509: 4842-4848 (2011)

[47] Kumar D, Dinesh Kumar N, Kalaiselvam S, Radhika R, Dash S, Tyagi A K, Jayavel R. Reactive magnetron sputtered wear resistant multilayer transition metal carbide coatings: microstructure and tribo-mechanical properties. RSC Advances 5: 81790-81801 (2015)

[48] Gilewicz A, Warcholinski B, Myslinski P, Szymanski W. Anti-wear multilayer coatings based on chromium nitride for wood machining tools. Wear 270: 32-38 (2010)

[49] Gilewicz A, Warcholinski B. Tribological properties of $\mathrm{CrCN} / \mathrm{CrN}$ multilayer coatings. Tribology International 80: 34-40 (2014)

[50] Beliardouh N E, Bouzid K, Nouveau C, Tlili B, Walock M J. Tribological and electrochemical performances of $\mathrm{Cr} / \mathrm{CrN}$ and $\mathrm{Cr} / \mathrm{CrN} / \mathrm{CrAlN}$ multilayer coatings deposited by $\mathrm{RF}$ magnetron sputtering. Tribology International 82: 443-452 (2015)

[51] Vyas A, Shen Y, Zhou Z, Li K Y. Nano-structured $\mathrm{CrN} / \mathrm{CNx}$ multilayer films deposited by magnetron sputtering. Composites Science and Technology 68: 2922-2929 (2008).

[52] Bayon R, Igartua A, Fernandez X, Martinez R, Rodriguez R J, Garcia J A, De Frutos A, Arenas M A, Damborenea J. Corrosion-wear behaviour of PVD $\mathrm{Cr} / \mathrm{CrN}$ multilayer coatings for gear applications. Tribology International 42: 591-599 (2009)

[53] Shi Y, Long S, Yang S, Pan F. Deposition of nano-scaled CrTiAlN multilayer coatings with different negative bias voltage on $\mathrm{Mg}$ alloy by unbalanced magnetron sputtering. Vacuum 84: 962-968 (2010)

[54] Gilewicz A, Warcholinski B. Deposition and characterisation of $\mathrm{Mo}_{2} \mathrm{~N} / \mathrm{CrN}$ multilayer coatings prepared by cathodic arc evaporation. Surface and Coatings Technology 279: 126-133 (2015)

[55] Ghosh S K, Limaye P K, Swain B P, Soni N L, Agrawal R G, Dusane R O, Grover A K. Tribological behaviour and residual stress of electrodeposited $\mathrm{Ni} / \mathrm{Cu}$ multilayer films on stainless steel substrate. Surface and Coatings Technology 201: 4609-4618 (2007)

[56] Gayathri S, Kumar N, Krishnan R, RavindranT R, Dash S, 
Tyagi A K, Raj B, Sridharan M. Tribological properties of pulsed laser deposited DLC/TM $(\mathrm{TM}=\mathrm{Cr}, \mathrm{Ag}, \mathrm{Ti}$ and $\mathrm{Ni})$ multilayers. Tribology International 53: 87-97 (2012)

[57] Liu D, Tu J, Zhang H, Chen R, Gu C D. Microstructure and mechanical properties of carbon nitride multilayer films deposited by DC magnetron sputtering. Surface and Coatings Technology 205: 3080-3086 (2011)

[58] Xu Z, Zheng Y J, Jiang F, Leng Y X, Sun H, Huang N. The microstructure and mechanical properties of multilayer diamond-like carbon films with different modulation ratios. Applied Surface Science 264: 207-212 (2013)

[59] Bewilogua K, Bialuch I, Ruske H, Weigel Kai. Preparation of a-C:H/a-C:H:Si:O and a-C:H/a-C:H:Si multilayer coatings by PACVD. Surface and Coatings Technology 206: 623-629 (2011)

[60] Liu Y, Gubisch M, Hild W, Scherge M, Spiess L, Knedlik C H, Schaefer J A. Nanoscale multilayer WC/C coatings developed for nanopositioning, part II: Friction and wear. Thin Solid Films 488: 140-148 (2005)

[61] Braic M, Balaceanu M, Parau A C, Dinu M. Vladescu A. Investigation of multilayered $\mathrm{TiSiC} / \mathrm{NiC}$ protective coatings. Vacuum 120: 60-66 (2015)

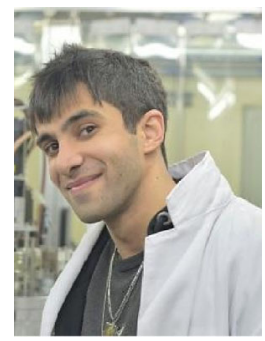

Mahdi KHADEM. He received his bachelor degree in mechanical engineering (solid design) from Qazvin International Azad University (QIAU) in 2013. After then, he joined the

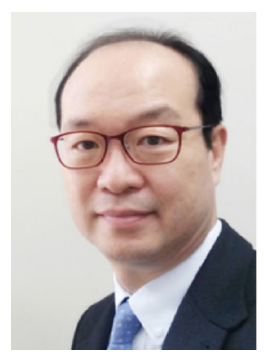

Dae-Eun KIM. He is currently a professor in the School of Mechanical Engineering and the Director of the Center for Nano-Wear (CNW) at Yonsei University. Prof. Kim received his B.S. degree from Tufts Univ., and M.S. and Ph.D. degrees from M.I.T. He was an assistant professor at the
[62] Braic M, Braic V, Balaceanu M, Zoita C N, Kiss A, Vladescu A, Popescue A, Ripeanu R. Structure and properties of $\mathrm{Zr} / \mathrm{ZrCN}$ coatings deposited by cathodic arc method. Materials Chemistry and Physics 126: 818-825 (2011)

[63] Ge F, Zhou X, Meng F, Xue Q, Huang F. Tribological behavior of $\mathrm{VC} / \mathrm{Ni}$ multilayer coatings prepared by nonreactive magnetron sputtering. Tribology International 99: 140-150 (2016)

[64] Zubarev E N, Devizenko A, Penkov O V, Kondratenko V V, Sevriukov D V, Sevryukova V A, Kopylets I A. Structural and phase transformation of cobalt films grown on amorphous carbon. Thin Solid Films 622: 84-88 (2017)

[65] Ou J, Liu L, Wang J, Wang F, Xue M, Li W. Fabrication and tribological investigation of a novel hydrophobic polydopamine/graphene oxide multilayer film. Tribology Letters 48: 407-415 (2012)

[66] Jehn H. Multicomponent and multiphase hard coatings for tribological applications. Surface and Coatings Technology 131: 433-440 (2000)

[67] Chauhan K V, Rawal S K. A Review Paper on Tribological and Mechanical Properties of Ternary Nitride based Coatings. Procedia Technology 14: 430-437 (2014)

Center for Nano Wear (CNW) and obtained his M.S. degree from Yonsei University, in 2015. He is currently a Ph.D. student at the same center. His research interests include tribology, coating and surface design, and nanotechnology.

Ohio State University before joining Yonsei University in 1993. He served as the Editor-in-Chief of IJPEM and Senior Editor of JMST. He is also the Chair of the Technical Committee for Tribology of International Federation for the Promotion of Mechanism and Machine Science (IFToMM). His research interests are micro/nano-tribology, functional coatings, and surface modification techniques. 